Journal home page: http://chimie-biologie.ubm.ro/carpathian_journal/index.html

\title{
IMPACT OF FREEZING AND DRYING PREPROCESSING ON PIGMENTS EXTRACTION FROM THE BROWN SEAWEED«PHYLLARIA RENIFORMIS» COLLECTED IN ALGERIAN COAST
}

\author{
Nora Ghaliaoui ${ }^{1,2,3}{ }^{凶}$, Hind Mokrane ${ }^{3}$, Mohammed Hazzit ${ }^{1}$, Mohammed Hadjadj², Fayçel Said \\ Otmani $^{2}$, Souad Touati ${ }^{2}$, Halima Seridi ${ }^{4}$ \\ ${ }^{I}$ Department de Technologie Alimentaire et Nutrition Humaine, Ecole Nationale Supérieure d'Agronomie, El- \\ Harrach (ENSA), Algiers, Algeria. \\ ${ }^{2}$ Centre de Recherche Scientifique et technique en Analyses Physico-Chimiques (CRAPC), Tipaza, Algeria. \\ ${ }^{3}$ Laboratoire de Recherche sur les Produits Bioactifs et Valorisation de la Biomasse, Département de Chimie, \\ Ecole Normale Supérieure de Kouba, Algiers, Algeria. \\ ${ }^{4}$ Laboratoire d'Océanographie Biologique et Environnement Marin, Université des sciences et de la technologie \\ Houari Boumediene, (USTHB), BP 32 Al Alia, Bab Ezzouar, Algiers, Algeria. \\ $\triangle_{\text {noragh50@yahoo.com }}$ \\ https://doi.org/10.34302/crpjfst/2020.12.3.6
}

Article history:

Received:

5 January 2019

Accepted:

15 August 2020

Keywords:

Preprocessing

Freezing

Drying

Phyllaria reniformis

Pigments

\begin{abstract}
Seaweeds are an excellent source of natural pigments such as chlorophylls and carotenoids that exhibit several bioactive properties fully exploited in food and health products. Due to the high sensitivity and the rapid degradation of pigments, recent researches are now focusing on development of efficient techniques for their extraction, while the sample preprocessing as the main important step attracted less attention. The objective of this study was the evaluation of the effect of freezing and drying preprocessing on pigments quantity, quality and antioxidant activity of the brown seaweed Phyllaria reniformis. Pigments were quantified using UVVisible spectrophotometry and fully characterized by reverse phase high performance liquid chromatography (RP-HPLC). Phyllaria reniformis was characterized by a high amount of pigments especially fucoxanthin. Based on UV-visible spectrophotometry results, alga preprocessing before extraction showed a high variability on pigments content. As shown by RPHPLC freezing preprocessing exhibited the most efficient pigment extraction in term of quantity. While, drying preprocessing demonstrated higher amount of $\beta$-carotene and pheophytin $a$. The highest and most efficient antioxidant activities were obtained in the frozen samples. The quality, quantity and antioxidant activities of Phyllaria reniformis pigments extract was found to be deeply related to the preprocessing step.
\end{abstract}

\section{Introduction}

Nowadays marine macro-algae commonly known as seaweeds have been extensively used in food (Durmaz et al., 2008; Bocanegra et al., 2009; Anis et al., 2017), agricultural (Ramya et al., 2015), pharmaceutical (Raman and Doble 2015) and cosmetic areas (Fabrowska et al., 2015).They represent a natural source of bioactive compounds as they are able to produce a great variety of secondary metabolites such as pigments, flavonoids, polyphenols characterized by several biological proprieties (Lim et al., 2002; Kudaa et al., 2005; Duan et al., 2006; Lordan et al., 2011; Vairappan et al., 2011; Rajauria et al., 2013; Sivaramakrishnan et al., 2017).

In the past decade, natural pigments were researched for their safety and health benefits 
compared to the synthetic ones. Macro-algae are renewable source of natural pigments such as chlorophylls and carotenoids (Hegazi et al., 1998; Durmaz et al., 2008). These Pigments have shown many biological activities as antioxidant (Yan et al., 1999; Sachindra et al., 2007; Hsu et al., 2013), anti-obesity (Maeda et al., 2007), chemotherapeutic (Hosokawaa et al., 2004) and anti-inflammatory activities (Shiratori et al., 2005).Brown seaweeds like the other classes of algae are rich on photosynthetic pigments in particular fucoxanthin and chlorophyll $c$ (Kumar et al., 2017).

Several methods were used for pigments extraction: Conventional or advanced (Kumar et al., 2010). For brown seaweed, the conventional method could be lengthy and difficult because of the thalli consistency mainly due to the polysaccharides. Therefore, innovative techniques allow obtaining algae pigments more quickly with higher yield and especially with reduced risk of their degradation. Multiple alternative extraction technologies have been suggested, such as ultrasounds, ultrasoundassisted enzymatic hydrolysis, microwaves, supercritical fluids, pulsed electric fields, highpressure homogenization and liquid pressurization (Le Guillard et al., 2016; Poojary et al., 2016; Mittal et al., 2017; Zhu et al., 2017).

Due to the high instability and easy degradation of pigments, new strategies for samples preprocessing before extraction must be suggested. Acid, enzymes, temperature, heat, light and oxygen, are the most important factors affecting the stability of naturals pigments. Although, many studies on algae pigments extraction and identification have been reported, little information is still available on the relation between pigments content and algae preprocessing. On the other hand, seaweed after their harvest are exposed to degradation, hence, drying and freezing are usually applied to minimize biological compounds degradation and conserve algae for long time.

Against this background, the main purpose of this work was the investigation of the effect of drying and freezing as preprocessing method on seaweed pigments quantity, quality and antioxidants activity. To the best of our knowledge, this is the first report on pigments characterization by spectrophotometer and by RP-HPLC analysis of Phyllaria reniformis collected from the Algerian coast and the effect of conservation method on seaweed pigments quality and quantity has also been understated.

\section{Materials and methods}

\subsection{Seaweed collection and preprocessing}

The brown seaweed Phyllaria reniformis was collected by hand at more than 15 meters depth from Tipaza (Algeria) in June. After a first rinse on-site with sea water, samples were taken to the laboratory in isothermal boxes. Then, all samples were washed for a second time with fresh tap water to remove sand, epiphytes, shells and any sediment. Afterwards, distilled water was used for a third wash.

The fresh alga samples were divided in three parts. One part was dried at $38 \pm 1{ }^{\circ} \mathrm{C}$ for one week, another part was frozen at $-18^{\circ} \mathrm{C}$ for one week and the last part was immediately prepared for extraction. All these steps were performed in low light and as quickly as possible to prevent pigment degradation.

\subsection{Extraction of seaweed pigments}

The fresh, frozen and dried alga samples were cut into small pieces of 3 to $5 \mathrm{~mm}$ and mixed with acetone at a ratio of $1 / 3(\mathrm{w} / \mathrm{v})$. Pigments were extracted in an ultrasonic bath in the following conditions: Power $100 \mathrm{~W}$ and $20 \mathrm{~Hz}$ for $90 \mathrm{~min}$ at $24^{\circ} \mathrm{C}$.

Then, all the obtained extracts were filtered and the solvent was evaporated using rotary evaporator at $28^{\circ} \mathrm{C}$. The obtained residues were lyophilized and stored at $-20^{\circ} \mathrm{C}$ in brown glass flasks for later analysis.

\subsection{Chlorophylls and carotenoids content}

To estimate the chlorophylls and carotenoids contents in samples, $100 \mathrm{mg}$ of dry extract were mixed with $2 \mathrm{~mL}$ of solvent and filtered using Nylon microfilter $(0.45 \mu \mathrm{m})$. The Absorption (Abs) of pigments in the filtrate was recorded in 
the range of $350-800 \mathrm{~nm}$ by UV-Visible Spectrophotometry (SPECORD 210 PLUS 623F1138, Germany). The content of chlorophyll $a, b, c$, Fucoxanthin and total carotenoids were calculated according to the equation of Lichtenthaler and Wellburn (1983) and Seely et al., (1972).

$$
\begin{aligned}
& {\left[C_{a}\right]=11.75 \times A b s_{662}-2.35 \times A b s_{665}} \\
& {\left[C_{b}\right]=18.61 \times A b s_{645}-3.96 \times A b s_{662}} \\
& {\left[C_{c}\right]=\left(A b s_{631}+A b s_{581}-0.3 A b s_{664}\right) / 62.2} \\
& {[F x]=\left(A b s_{470}-1.239 \times\left(A b s_{631}+A b s_{581}\right.\right.} \\
& \left.-0.3 \times A b s_{664}\right) \\
& \left.-0.0275 \times A b s_{664}\right) / 141 \\
& {[\text { Tot Carot }]=\left(1000 \times A b s_{470}-2.27 \times C_{a}\right.} \\
& \left.-81.4 \times C_{a b}\right) / 227
\end{aligned}
$$

Where:

Abs is the absorbance in the specified wavelength

$C_{a}$ is the concentration of chlorophyll $a$

$C_{b}$ is the concentration of chlorophyll $b$

$C_{c}$ is the concentration of chlorophyll $c$

Tot Carot is the total carotenoids

$F x$ is the fucoxanthin

\subsection{High performance liquid chromatography pigments Analysis}

The separation of seaweed pigments was conducted by analytical HPLC (Agilent 1100, USA) equipped with UV-Visible detector. The column was $\mathrm{C} 18,5 \mu \mathrm{m}, 150 \times 4.6 \mathrm{~mm}$. The injection loop size was $20 \mu$ l. The used method was inspired from the study of Wright (1991).The column was equilibrated using a gradient of elution of solvent A (methanol: $0.5 \mathrm{M}$ ammonium acetate, 80:20 v/v) and solvent B (Acetonitrile: water, 90:10 v/v), solvent C (ethyl acetate). The flow rate was $1 \mathrm{~mL} / \mathrm{min}$, and the gradient was as follows (minutes; \% solvent $\mathrm{A}$; $\%$ solvent $\mathrm{B} ; \%$ solvent C): $(0 ; 100 ; 0 ; 0),(4 ; 0$; $100 ; 0),(18 ; 0 ; 20 ; 80),(21 ; 0 ; 100 ; 0)$, $(22 ; 100 ; 0 ; 0),(25 ; 100 ; 0 ; 0)$. The column equilibration was $10 \mathrm{~min}$. Pigments were detected by recording Abs at $440 \mathrm{~nm}$. All these steps were carried out at room temperature. The obtained HPLC peaks were identified by comparing the retention times with those of standards pigments.

\subsection{Pigments standards}

The authentic standard pigments Chlorophylls ( $a, b, \quad c_{1}+c_{2}$ and $\left.c_{3}\right)$, Chlorophyllides $a$ and fucoxanthin were obtained from Sargassum vulgare by semi preparative HPLC and to confirm the purification, each pigment was chromatographed in the analytical column $\mathrm{C} 18$ and $\mathrm{C} 8$. The same gradient was used with a flow rate of $5 \mathrm{~mL} / \mathrm{min}$. Each pigment was collected at the outlet of the detector, isolated immediately from solvent by evaporation. Pheophytin $a$ was obtained by acidification of chlorophyll $a$ with $1 \mathrm{M}$ of hydrochloric acid (HCl) (Wright 1991). The identification of separated pigments was confirmed from their visible spectral absorption and compared with the literature (Pereira et al., 2014). Visible spectra were obtained with UVVisible Spectrophotometer (SPECORD 210 PLUS 623F1138, Germany). $\beta$-Carotene was purchased from Sigma Aldrich.

\subsection{DPPH radical scavenging activity}

The pigment extracts antioxidant activity was evaluated using a modified method previously described by (Menaceur et al., 2013) and (Hazzit et al., 2009) $25 \mu \mathrm{L}$ of each sample at different concentrations (from 0 to $100 \mu \mathrm{g} / \mathrm{mL}$ dissolved in methanol) were added to $1975 \mu \mathrm{L}$ of 2,2-diphenylpicrylhydrazyl (DPPH) solution $(0.0024 \%)$ and incubated for $30 \mathrm{~min}$ in the dark at room temperature. The Abs was measured at $517 \mathrm{~nm}$ with UV-Visible spectrophotometer (SPECORD 210 PLUS 623F1138, Germany). Butylated hydroxytoluene (BHT) and Butylated hydroxyanisole (BHA) were used as standard and all measurements were done in triplicates. The DPPH radical scavenging activity was calculated using the following equation:

Scavenging activity $(\%)=\left(A b s_{b}-\right.$ $\left.A b s_{s} / A b s_{b}\right) \times 100$; Where $\mathrm{Abs}_{\mathrm{s}}$ is the sample Abs after 30 min and $\mathrm{Abs}_{\mathrm{b}}$ is the sample Abs before reaction. The concentration providing $50 \%$ inhibition $\left(\mathrm{IC}_{50}\right)$ of samples was calculated 
using the graph by plotting inhibition percentage against concentration.

\subsection{Statistical Analysis}

All the analysis was run in triplicate. The data are presented as Mean \pm Standard error. The Statistical Package for Social Science (SPSS Version: 20) was used for the analysis. One-way analysis of variance (ANOVA) was performed and comparison of data for significant differences $(p$-value $\leq 0.05)$ was made with Tukey's HSD test.

\section{Results and discussions}

\subsection{UV-Visible absorption spectra of} pigments extract

Chlorophylls and carotenoids represent the major group of photosynthetic pigments found in plants and in algae. Each group has multiple types of pigment that can be identified by the specific wavelength. Pigments absorb on only specific wavelengths of visible light while reflecting the others; the reflected light is color.
The set of wavelengths absorbed by a pigment is its absorption spectrum.

Figure 1 shows the absorption spectrum of the obtained pigment extracts recorded from 350 to $800 \mathrm{~nm}$. All the pigments extracts absorb mostly in the blue (between 400 and 500nm) and red (between 600 and $700 \mathrm{~nm}$ ) visible spectral regions. A high Abs was observed in pigments extract obtained after freezing preprocessing followed by that obtained after drying preprocessing while the low Abs was recorded in the extract of fresh alga.

The broad absorption in the blue and red regions is probably due to the presence of carotenoids, chlorophyll $a$ and chlorophyll $b$ in the three pigments extracts. Each pigment has unique Abs spectra, whereas carotenoids absorb visual light broadly in the blue spectral range from 400 to $500 \mathrm{~nm}$, whilst chlorophyll $a$ and chlorophyll $b$ absorb with narrow bands maximally in the blue (near 430 and 453nm) and red (near 662 and $642 \mathrm{~nm})$.

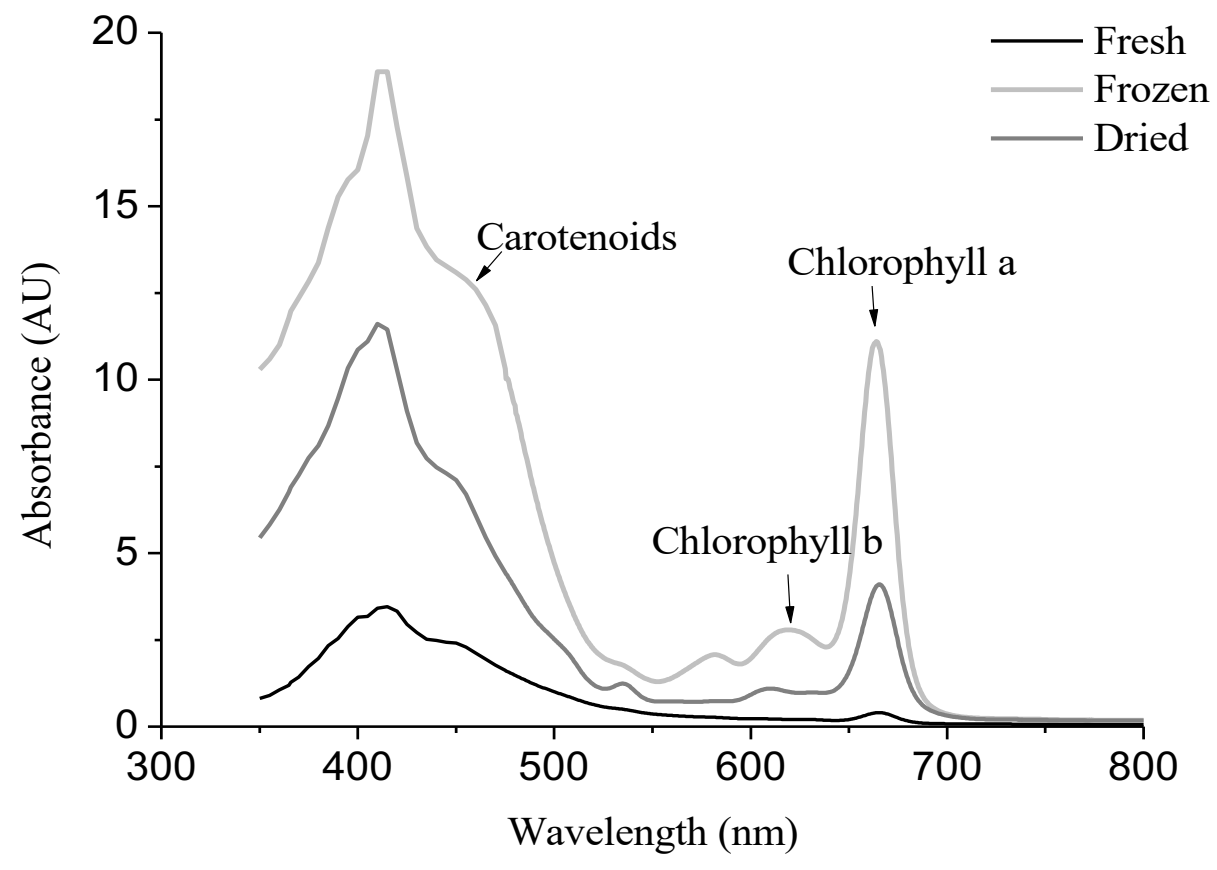

Figure 1. Absorbance spectra of pigments extract from fresh, frozen and dried Phyllaria reniformis. 


\subsection{Chlorophylls and carotenoids contents}

Chlorophylls and carotenoids content in the three pigment extracts (dry, fresh and frozen) were determined by UV-Visible spectrophotometry and presented on figure 2 for Chlorophyll $a, b$ and $c$ and figure 3 for fucoxanthin and total carotenoids.

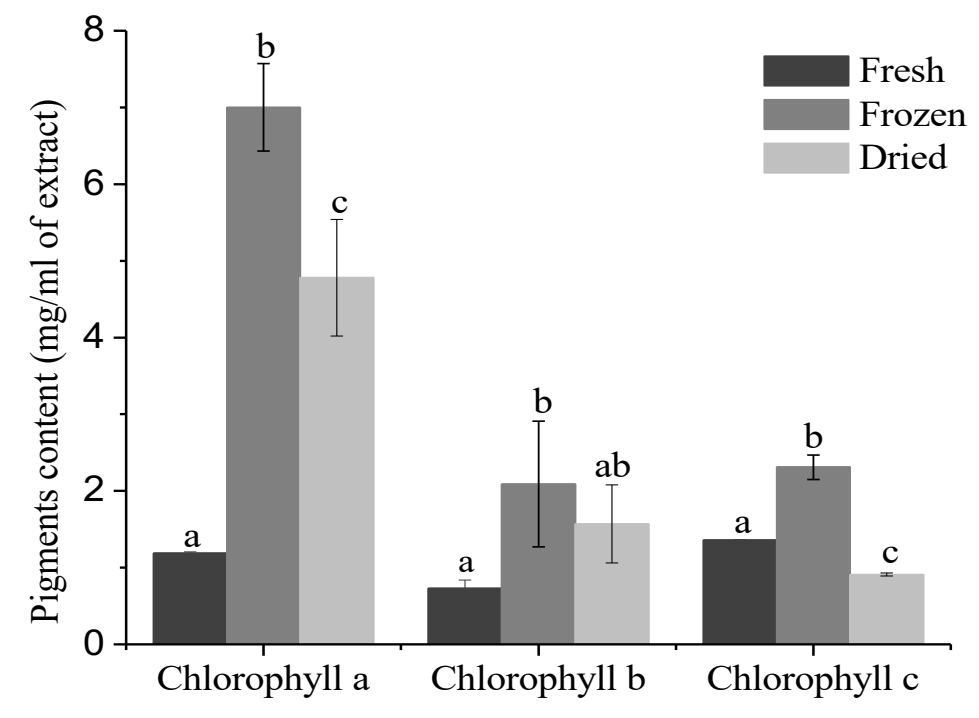

Figure 2. Chlorophylls content in pigments extracts obtained from the fresh, frozen and dried brown alga Phyllaria reniformis (Mean \pm SD). Within any given pigment, bars with different letters indicate significant differences between alga preprocessing types ( $p$-value $\leq 0.05$, Tukey's HSD test)

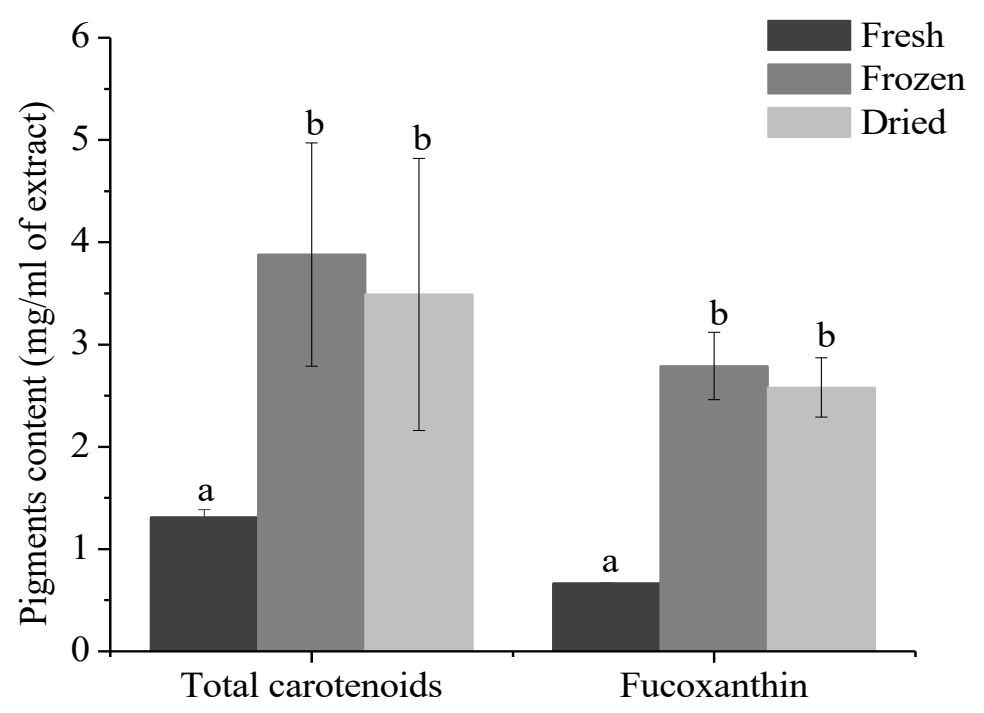

Figure 3. Total carotenoids and fucoxanthin content in pigments extracts obtained from the fresh, frozen and dried brown alga Phyllaria reniformis (Mean \pm SD). Within any given pigment, bars with different letters indicate significant differences between alga preprocessing types ( $p$-value $\leq 0.05$, Tukey's HSD test) 
Results showed a variability of quantities for each pigment in relation to the applied preprocessing. For Chlorophyll $a, b$, fucoxanthin and total carotenoids, the highest amount were reported in frozen sample extract $(7.00 \pm 0.57,2.09 \pm 0.82,2.79 \pm 0.33,3.88 \pm$ $1.09 \mathrm{mg} / \mathrm{mL}$ respectively) followed by the dried one $(4.78 \pm 0.76,1.57 \pm 0.51,2.58 \pm 0.29,3.49$ $\pm 1.33 \mathrm{mg} / \mathrm{mL}$ respectively) and the lowest amount of these pigments were found in the fresh sample $(1.19 \pm 0.01,0.73 \pm 0.11,0.66 \pm$ $0.00,1.31 \pm 0.07 \mathrm{mg} / \mathrm{mL}$ respectively).

The highest value for chlorophyll $c$ was found in the frozen extract $(2.31 \pm 0.16 \mathrm{mg} / \mathrm{mL})$ followed by the fresh alga extract $(1.31 \pm 0.36$ $\mathrm{mg} / \mathrm{mL}$ ), however the lowest have been demonstrated in extract obtained after drying preprocessing $(0.91 \pm 0.02 \mathrm{mg} / \mathrm{mL})$.

The analysis of variance showed a significant effect of preprocessing on pigments contents ( $p$ value $\leq 0.05)$. However, the pairwise comparisons using Tukey's HSD test revealed that for both, total carotenoid and fucoxanthin, no significant difference was found between drying and freezing preprocessing, but for chlorophylls ( $a$ and $c$ ) it was statistically significant. This test revealed also a significant difference between fresh and frozen samples extracts in chlorophylls $(a, b, c)$, fucoxanthin and total carotenoid.

The freezing preprocessing of alga before pigments extraction gave the highest yields; this is probably due to the degradation of the thalli by freezing effect. Whilst the drying preprocessing revealed also an important pigments yield compared to the fresh one, but chlorophyll $c$ was underestimated due to the low water content in the dried alga.

The use of UV-Visible spectrophotometry for quantitative determination of chlorophylls and carotenoids is complicated. Due to a similarity in the Abs spectra of some pigments, there could be an underestimation or an overestimation, therefore concentration of total chlorophylls and total carotenoids could accurately be estimated, however individual pigment concentration was difficult to be resolved (Thrane et al., 2015).

Furthermore, the determination of the pigment content may have unfair value due to the formation of new products such as pheophytins and chlorophyllides resulting from pigment degradation and having similar wavelength absorption to the original pigment. For that reason, the high content of chlorophyll $a$ may be related to chlorophyll $c$ that was abounded in brown seaweeds, and it may result to their degradation to pheophytin $a$ and chlorophyllide a. Moreover, the accuracy of UV-Visible spectrophotometric method is also affected by other facts such as the solvent used for extraction, the type of sample, the sample preprocessing and also the spectrophotometer used (Haryatfrehni et al., 2015; Ritchie 2018).

\subsection{HPLC analysis}

HPLC is considered as an efficient method for measuring pigment concentrations in plant and algae. This technique can resolve most chlorophylls and carotenoids, including their degradation products such as pheophytins (Mantoura and Llewellyn 1983)

Table 1 lists the photosynthetic pigments separated of samples extracts and their retention times. Figure 4 shows typical chromatograms $(\mathrm{A}, \mathrm{B}, \mathrm{C})$ resulting from RP-HPLC analysis of pigments extracts from respectively fresh, frozen and dried alga samples.

For each sample a good resolution of the major pigments was achieved. Twelve peaks indicating pigments were resolved, as shown in table 1. At the polar end of the chromatogram, chlorophyllides $a$, chlorophyll $c 3$, and chlorophylls $c 1, c 2$ were almost resolved, however in the central region of the chromatogram, fucoxanthin, trans-neoxanthin and two unidentified components were presented; while at the non-polar end of chromatogram, chlorophylls $a$ and $b$, pheophytin $a$ and $\beta$-carotene were resolved. 
Table 1. Photosynthetic pigments of Phyllaria reniformis extract (Fresh, Frozen, Dried)

\begin{tabular}{|l|l|l|l|l|l|}
\hline Peak & Retention time (min) & Pigment & Fresh & Fozen & Dried \\
\hline 0 & 1.55 & Solvent & + & + & + \\
\hline 1 & 3.92 & Chlorophyllide $a$ & + & + & + \\
\hline 2 & 4.84 & Chlorophyll $c 3$ & + & + & + \\
\hline 3 & 5.68 & Chlorophyll $c 1, c 2$ & + & + & + \\
\hline 4 & 7.38 & Fucoxanthin & + & + & + \\
\hline 5 & 8.48 & Trans-neoxanthin & + & + & + \\
\hline 6 & 8.78 & UNK $*$ & + & + & + \\
\hline 7 & 9.34 & UNK & + & - & + \\
\hline 8 & 14.38 & Chlorophyll $b$ & + & + & - \\
\hline 9 & 14.96 & Chlorophyll $a$ & + & + & + \\
\hline 10 & 15.08 & Chlorophyll $a$ & + & + & + \\
\hline 11 & 16.73 & phaeophytins & + & + & + \\
\hline 12 & 17.50 & $\beta$ Carotene & + & + & + \\
\hline a & 6.46 & UNK & - & - & + \\
\hline b & 16.25 & UNK & - & - & + \\
\hline c & 17,11 & UNK & - & - & + \\
\hline
\end{tabular}

UNK: unknow

In all, chromatogram of fresh alga (Figure 4.A) was dominated by fucoxanthin, followed by chlorophyll $a$, then chlorophyll $c 1+c 2$. These three pigments are the main pigments in brown algae, which impart a greenish brown color to the algae (Kadam et al., 2013).Chlorophyll $c 1$ and $c 2$ are only found in phaeophyceae (Rowan 1989). Smaller amounts of chlorophyllides $a$, chlorophyll $c 3$, chlorophyll $b$, pheophytin $a$ and $\beta$-carotene were also resolved. The same resolution was found in the frozen alga sample (Figure 4.B) but with higher peaks.

Chromatogram of the dried pre-proceeded sample (Figure 4.C) shows also a high amount of fucoxanthin and chlorophyll $a$, and a lower amount of chlorophyll $b$, with lower peak intensity in comparison to that of freezing preprocessing but superior to that of the fresh sample. However, in the same sample, chlorophyll $c 1+c 2$ was less abundant compared to the fresh and frozen ones, this might be caused by the high polarity of chlorophylls $c$. Another possible reason may be the percentage of water missing during solvent extraction by aqueous acetone in the dried sample which may lead to a lower diffusion of chlorophylls $c$ than that in both fresh and frozen samples. Therefore, drying sample before extraction might be suitable for extraction of hydrophobic compounds (nonpolar) probably because of the lower water content.

$\beta$-carotene is completely hydrophobic hence, it was presented by the highest intensity peak compared to fresh and frozen samples. According to Seely et al., (1972) dimethyl sulphoxide (DMSO) a more polar solvent was shown to extract much of the chlorophyll $c$ and fucoxanthin from the intact thalli of brown algae, while subsequent extraction with acetone rapidly removes most of the chlorophyll $a$ and $\beta$ carotene. 

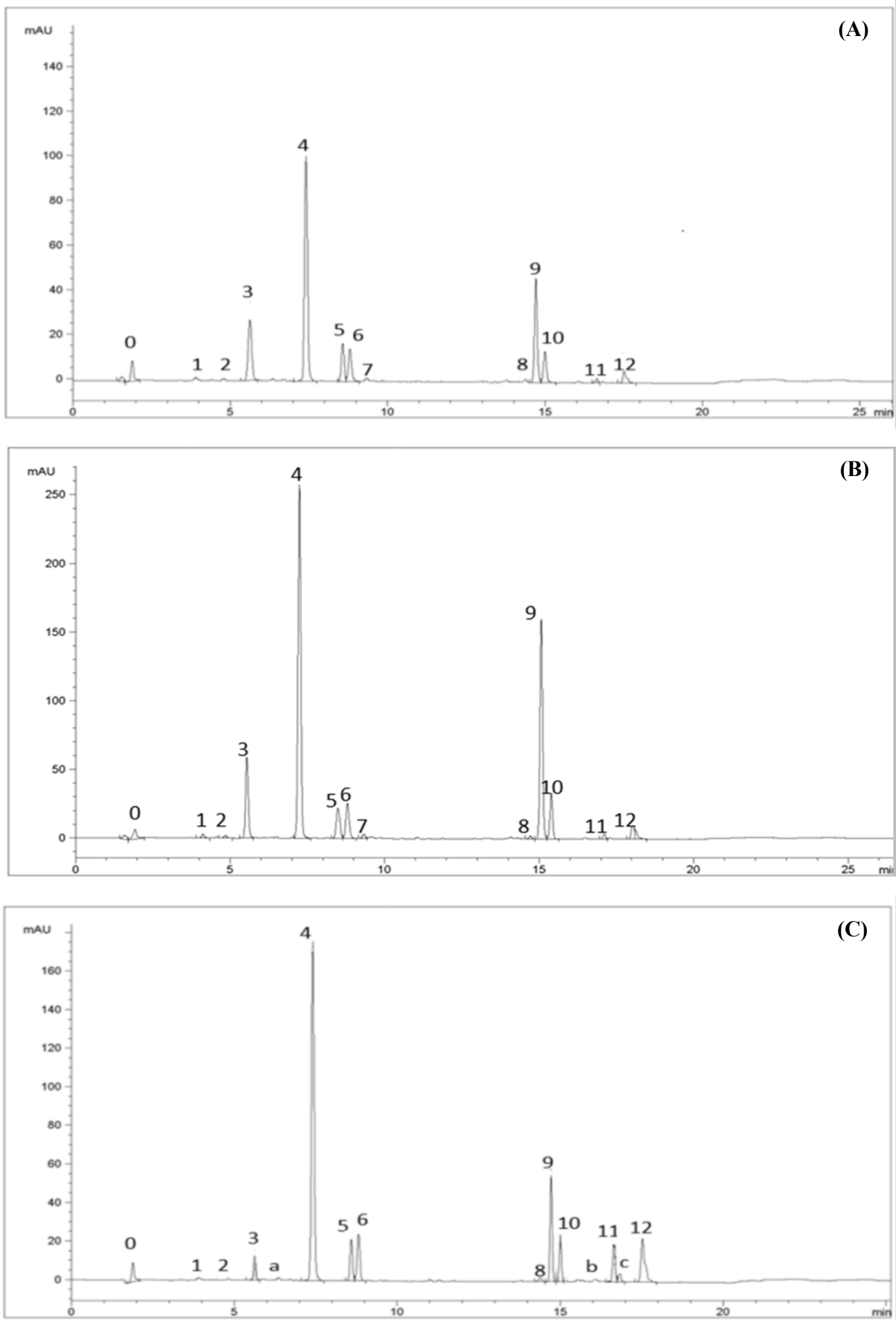

Figure 4. Chromatogram separation of pigment extracts from the fresh (A), the Frozen (B) and the dried (C) brown algae Phyllaria reniformis. 
Similar result was observed for pheophytin $a$, a hydrophobic pigment highly present in the dried sample probably due to the degradation of chlorophyll $a$. When the chlorophylls were exposed to heat or acidic conditions, the magnesium ion is lost from their structure and the resulting molecule was (pheophytin) which exhibits olive-green color (Mohamed et al., 2012). Other traces of pigments are present in the dried sample chromatogram such as the unknown (peaks a, b, c) which may indicate that a little degradation had occurred.

Based on these results it can be assumed that Phyllaria reniformis drying before pigments extraction can lead to a selection of pigments especially $\beta$-carotene. However, Hynstova et al., (2018) concluded that the processing of Chlorella vulgaris and Spirulina platensis dried powder will lead to a decrease $\beta$-carotene content, probably due to heat or light exposure. The study of Tang and Chen (2000) on the stability and degradation of freeze-dried carotenoids powder showed that the amount of $\beta$-carotene and lutein decreased with increasing storage temperature. Several researchers demonstrated that carotenoids tend to decrease with increasing drying time due to oxidation and isomerization (Anguelova and Warthesen 2000; Karabuluta et al., 2007). According to Chan et al., (1997) the nutritional composition including pigments of seaweed Sargassum hemiphyllum is greatly affected by different drying methods.

\subsection{Antioxidant activity}

In comparison with red and green seaweeds, brown seaweeds are characterized by higher antioxidant potential. Several researches demonstrated that brown algae extracts and especially algae pigments are comparatively similar or superior to synthetic antioxidants due to the presence of carotenoid and fucoxanthin (Tutour et al., 1998; Sudhakar et al., 2013; Kosanić et al., 2019). Moreover, chlorophylls, pheophytins and carotenoids are known to act as antioxidants to prevent oxidative DNA damage and lipid peroxidation (Lanfer-Marquez et al., 2005; Heo et al., 2008; Sindhu et al., 2010; Hsu et $a l ., 2013)$. In the present study the antioxidant abilities of pigments extracts were evaluated by scavenging of DPPH radical. The scavenging effect increased with the increasing sample concentrations as shown in figure 5.

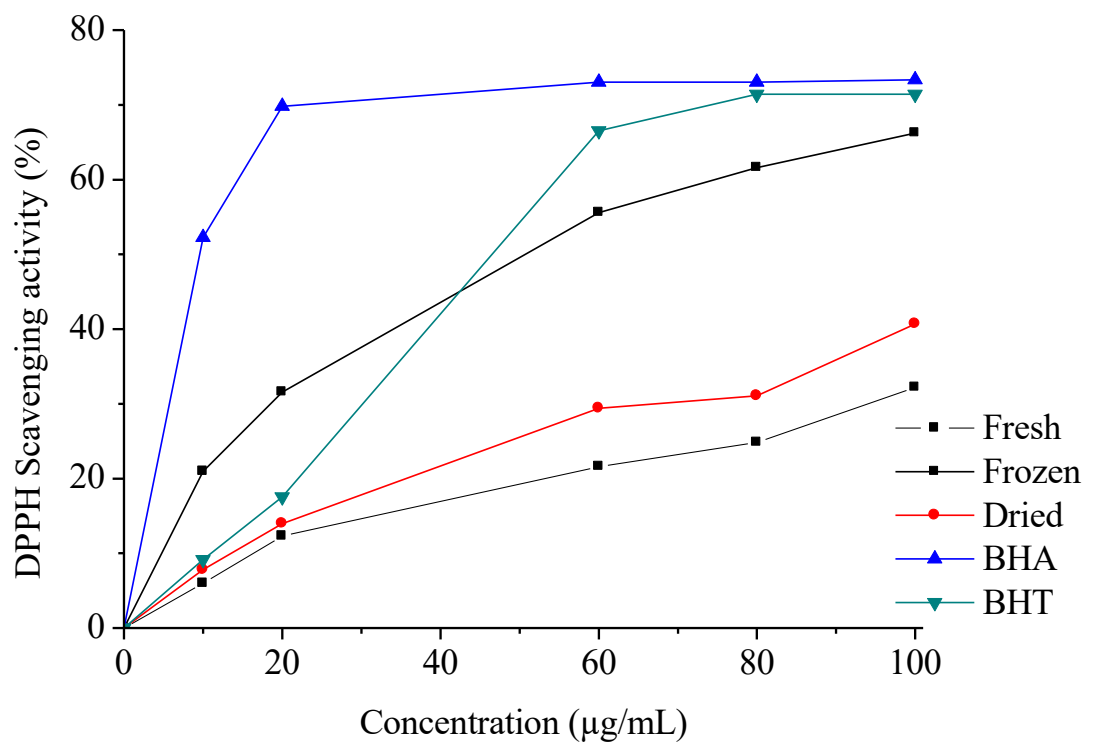

Figure 5. Free radical-scavenging capacities of reference antioxidant (BHA, BHT) and pigments extracts obtained from the fresh, frozen and dried brown alga Phyllaria reniformis, (Mean \pm SD) 
All pigment extracts from fresh, dried and frozen alga exhibited antioxidant activity. The frozen sample extract (at a concentration exceeding $60 \mu \mathrm{g} / \mathrm{mL}$ ) showed significant activity almost similar to BHA and BHT. In the same sample, the maximum alga pigment extract concentration used $(100 \mu \mathrm{g} / \mathrm{mL})$ exhibited more than $80 \%$ of radical inhibition while those extracted from the dried and fresh sample extracts showed lower activities $50.82 \%$ and $32.17 \%$, respectively.
The effectiveness of antioxidant properties is inversely correlated with their $\mathrm{IC}_{50}$ values representing the concentration of extracts at which they scavenge the $50 \%$ of the DPPH solution. The lower the $\mathrm{IC}_{50}$ value of an antioxidant the higher would be its free radical scavenging power. Figure 6 displays comparison of the $\mathrm{IC}_{50}$ values of $\mathrm{BHA}$ and $\mathrm{BHT}$ as standards with those of pigments extracts.

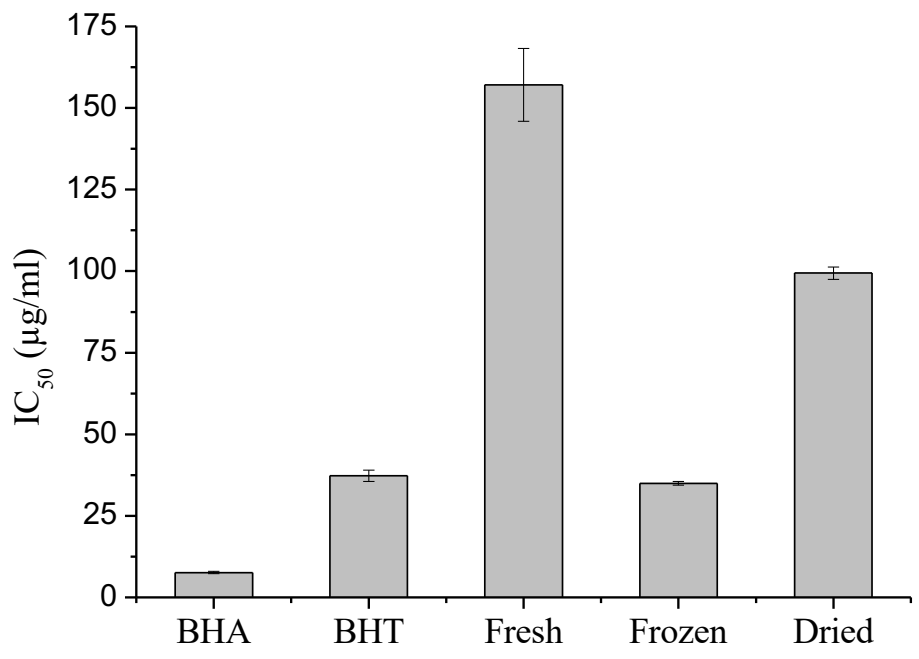

Figure 6. $\mathrm{DPPH}\left(\mathrm{IC}_{50}\right)$ values of reference antioxidants $(\mathrm{BHA}, \mathrm{BHT})$ and pigments extracts obtained from the fresh, frozen and dried brown alga Phyllaria reniformis, (Mean $\pm \mathrm{SD}$ )

Pigments extract obtained after frozen preprocessing was the most efficient by the lowest $\mathrm{IC}_{50}$ values of $34.96 \pm 0.6 \mu \mathrm{g} / \mathrm{ml}$ among all extracts and BHT reference antioxidant, and it was less efficient compared to BHA reference antioxidant. A low antioxidant activity was observed in the fresh sample extract with 157.09 $\pm 11.14 \mu \mathrm{g} / \mathrm{ml}$ of $\mathrm{IC}_{50}$ value. While the $\mathrm{IC}_{50}$ of the dried sample extract was $99.39 \pm 1.90 \mu \mathrm{g} / \mathrm{ml}$. The analysis of variance showed a significant difference between the pigments extracts ( $p$ value $\leq 0.05$ ). This difference is probably due to the effect of the preprocessing of the alga before pigments extraction.

\section{Conclusions}

Marine algae are an excellent source of biologically active compounds for pharmaceutical, food, cosmetic sectors. Seaweed could be exploited as a good source of natural pigments. Consequently, for appropriate pigments extraction method, the preprocessing step of algae before extraction remains the most important because of the highest sensitivity of pigments. This study showed the effect of drying and freezing preprocessing on quantity, quality and antioxidant activity of pigments extracts. Based on the obtained results from the spectrophotometric determination of chlorophylls and carotenoids and their separation by chromatography method (RPHPLC), the freezing preprocessing of alga was 
the most efficient technique to isolate high level of chlorophylls and carotenoids. The drying preprocessing gave also a fairly large amount of pigments compared to fresh alga especially for hydrophobic pigments such as $\beta$-carotene. This may be due to the small content of water in sample, in spite of that, drying could contribute to a loss of pigments justified by the presence of pheophytin $a$ probably produced after chlorophylls degradation and other pigments traces. According to DPPH scavenging activity results, Phyllarira reniformis could constitute a natural source of antioxidant substances of high importance. The highest activity was obtained in frozen sample extract. To sum up, this study offers to Phyllarira reniformis the opportunity to be used as a natural source of biocompounds in different fields, because of its richness in antioxidant pigments especially fucoxanthin. On the other hand, and from an economical point of view, freezing preprocessing is an appropriate method for pigments extraction with high efficiency. Freezing before pigments extraction could be employed to recover more pigments from algae in term of quality, because of alga thalli degradation, while the drying preprocessing led to the extraction of higher contains of the most stable pigments such as $\beta$ carotene. The choice of the suitable preprocessing technique before pigments extraction could direct the researcher to a specific pigment.

\section{References}

Anguelova, T. and J. Warthesen (2000). Lycopene Stability in Tomato Powders. Journal of Foood Science 65(1): 67-70.

Anis, M., Ahmed, S., \& Hasan, M. M. (2017). Algae as nutrition, medicine and cosmetic: The forgotten history, present status and future trends. World Journal of Pharmacy and Pharmaceutical Sciences, 6(6), 19341959.

Bocanegra, A., Bastida, S., Benedi, J., Rodenas, S., \& Sanchez-Muniz, F. J. (2009). Characteristics and nutritional and cardiovascular-health properties of seaweeds. Journal of medicinal food, 12(2), 236-258.

Chan, J. C. C., Cheung, P. C. K., \& Ang, P. O. (1997). Comparative studies on the effect of three drying methods on the nutritional composition of seaweed Sargassum hemiphyllum (Turn.) C. Ag. Journal of Agricultural and Food Chemistry, 45(8), 3056-3059.

Duan, X. J., Zhang, W. W., Li, X. M., \& Wang, B. G. (2006). Evaluation of antioxidant property of extract and fractions obtained from a red alga, Polysiphonia urceolata. Food chemistry, 95(1), 37-43.

Durmaz, Y., Duyar, H., Gokpinar, S., Taskaya, L., Ogretmen, Y., Bandarra, N., \& Nunes, M. (2008). Fatty Acids, $\alpha$-tocopherol and total pigment contents of Cystoseira spp., Ulva spp. and Zostera spp. from Sinop Bay (Turkey). International Journal of Natural and Engineering Sciences, 2(3), 111-114.

Fabrowska, J., Lęska, B., Schroeder, G., Messyasz, B., \& Pikosz, M. (2015). Biomass and extracts of algae as material for cosmetics. Marine Algae Extracts: Processes, Products, and Applications, 681-706.

Haryatfrehni, R., Dewi, S. C., Meilianda, A., Rahmawati, S., \& Sari, I. Z. R. (2015). Preliminary study the potency of macroalgae in yogyakarta: extraction and analysis of algal pigments from common gunungkidul seaweeds. Procedia Chemistry, 14, 373-380.

Hazzit, M., Baaliouamer, A., Veríssimo, A. R., Faleiro, M. L., \& Miguel, M. G. (2009). Chemical composition and biological activities of Algerian Thymus oils. Food chemistry, 116(3), 714-721.

Hegazi, M. M., Pérez-Ruzafa, A., Almela, L., \& Candela, M. E. (1998). Separation and identification of chlorophylls and carotenoids from Caulerpa prolifera, Jania rubens and Padina pavonica by reversedphase high-performance liquid chromatography. Journal of Chromatography A, 829(1-2), 153-159. 
Heo, S. J., Ko, S. C., Kang, S. M., Kang, H. S., Kim, J. P., Kim, S. H., Lee W., Cho M.G., \& Jeon, Y. J. (2008). Cytoprotective effect of fucoxanthin isolated from brown algae Sargassum siliquastrum against H 2 O 2induced cell damage. European food research and technology, 228(1), 145-151.

Hosokawa, M., Kudo, M., Maeda, H., Kohno, H., Tanaka, T., \& Miyashita, K. (2004). Fucoxanthin induces apoptosis and enhances the antiproliferative effect of the PPAR $\gamma$ ligand, troglitazone, on colon cancer cells. Biochimica et Biophysica Acta (BBA)-General Subjects, 1675(1-3), 113119.

Hsu, C. Y., Chao, P. Y., Hu, S. P., \& Yang, C. M. (2013). The antioxidant and free radical scavenging activities of chlorophylls and pheophytins. Food and Nutrition Sciences, 4(08), 1-8.

Hynstova, V., Sterbova, D., Klejdus, B., Hedbavny, J., Huska, D., \& Adam, V. (2018). Separation, identification and quantification of carotenoids and chlorophylls in dietary supplements containing Chlorella vulgaris and Spirulina platensis using High Performance Thin Layer Chromatography. Journal of pharmaceutical and biomedical analysis, 148, 108-118.

Kadam, S. U., Tiwari, B. K., \& O’Donnell, C. P. (2013). Application of novel extraction technologies for bioactives from marine algae. Journal of agricultural and food chemistry, 61(20), 4667-4675.

Karabulut, I., Topcu, A., Duran, A., Turan, S., \& Ozturk, B. (2007). Effect of hot air drying and sun drying on color values and $\beta$ carotene content of apricot (Prunus armenica L.). LWT-Food Science and Technology, 40(5), 753-758.

Kosanić, M., Ranković, B., \& Stanojković, T. (2019). Brown macroalgae from the Adriatic Sea as a promising source of bioactive nutrients. Journal of Food Measurement and Characterization, 13(1), 330-338.
Kuda, T., Tsunekawa, M., Goto, H., \& Araki, Y. (2005). Antioxidant properties of four edible algae harvested in the Noto Peninsula, Japan. Journal of food composition and analysis, 18(7), 625-633.

Kumar, N. J. I., M. Barot, \& Kumar, R. N. (2017). Distribution and biochemical constituents of different seaweeds collected from Okha coast, Gujarat, India. Indian Journal of Geo Marine Sciences 46(2): 349357.

Kumar, P., Ramakritinan, C. M., \& Kumaraguru, A. K. (2010). Solvent extraction and spectrophotometric determination of pigments of some algal species from the shore of Puthumadam, south east coast of India. International Journal of Oceans and Oceanography, 4(1), 29-34.

Lanfer-Marquez, U. M., Barros, R. M., \& Sinnecker, P. (2005). Antioxidant activity of chlorophylls and their derivatives. Food Research International, 38(8-9), 885-891.

Le Guillard, C., Bergé, J. P., Donnay-Moreno, C., Bruzac, S., Ragon, J. Y., Baron, R., Fleurence, J., \& Dumay, J. (2016). Soft liquefaction of the red seaweed Grateloupia turuturu Yamada by ultrasound-assisted enzymatic hydrolysis process. Journal of Applied Phycology 28(4): 2575-2585.

Lichtenthaler, H. K. and A. R. Wellburn (1983). Determinations of total carotenoids and chlorophylls $a$ and $b$ of leaf extracts in different solvents. Biochemical Society Transactions 11 (5): 591-592.

Lim, S. N., Cheung, P. C. K., Ooi, V. E. C., \& Ang, P. O. (2002). Evaluation of antioxidative activity of extracts from a brown seaweed, Sargassum siliquastrum. Journal of Agricultural and Food Chemistry, 50(13), 3862-3866.

Lordan, S., Ross, R. P., \& Stanton, C. (2011). Marine bioactives as functional food ingredients: potential to reduce the incidence of chronic diseases. Marine drugs, 9(6), 1056-1100. 
Maeda, H., Hosokawa, M., Sashima, T., \& Miyashita, K. (2007). Dietary combination of fucoxanthin and fish oil attenuates the weight gain of white adipose tissue and decreases blood glucose in obese/diabetic KK-Ay mice. Journal of Agricultural and Food Chemistry, 55(19), 7701-7706.

Mantoura, R. F. C. and C. A. Llewellyn (1983). The rapid determination of algal chlorophyll and carotenoid pigments and their breakdown products in natural waters by reverse-phase high-performance liquid chromatography. Analytica Chimica Acta 151: 297-314.

Menaceur, F., Benchabane, A., Hazzit, M., \& Baaliouamer, A. (2013). Chemical composition and antioxidant activity of Algerian Juniperus phoenicea L. extracts. Journal of Biologically Active Products from Nature, 3(1), 87-96.

Mittal, R., Tavanandi, H. A., Mantri, V. A., \& Raghavarao, K. S. M. S. (2017). Ultrasound assisted methods for enhanced extraction of phycobiliproteins from marine macroalgae, Gelidium pusillum (Rhodophyta). Ultrasonics sonochemistry 38: 92-103.

Mohamed, S., Hashim, S. N., \& Rahman, H. A. (2012). Seaweeds: a sustainable functional food for complementary and alternative therapy. Trends in Food Science \& Technology, 23(2), 83-96.

Pereira, D. M., Valentão, P., \& Andrade, P. B. (2014). Marine natural pigments: Chemistry, distribution and analysis. Dyes and Pigments, 111, 124-134.

Poojary, M. M., Barba, F. J., Aliakbarian, B., Donsì, F., Pataro, G., Dias, D. A., \& Juliano, P. (2016). Innovative alternative technologies to extract carotenoids from microalgae and seaweeds. Marine drugs, 14(11), 214.

Rajauria, G., Jaiswal, A. K., Abu-Gannam, N., \& Gupta, S. (2013). Antimicrobial, antioxidant and free radical-scavenging capacity of brown seaweed Himanthalia elongata from western coast of
Ireland. Journal of Food

Biochemistry, 37(3), 322-335.

Raman, M., \& Doble, M. (2015). к-Carrageenan from marine red algae, Kappaphycus alvarezii-A functional food to prevent colon carcinogenesis. Journal of functional foods, 15, 354-364.

Ramya, S. S., Vijayanand, N., \& Rathinavel, S. (2015). Foliar application of liquid biofertilizer of brown alga Stoechospermum marginatum on growth, biochemical and yield of Solanum melongena. International Journal of Recycling of Organic Waste in Agriculture, 4(3), 167-173.

Ritchie, R. J. (2018). Measurement of chlorophylls $a$ and $b$ and bacteriochlorophyll $a$ in organisms from hypereutrophic auxinic waters. Journal of Applied Phycology 30(6): 3075-3087.

Rowan, K. S. (1989). Photosynthetic pigments of algae. Cambridge University Press CUP Archive.

Sachindra, N. M., Sato, E., Maeda, H., Hosokawa, M., Niwano, Y., Kohno, M., \& Miyashita, K. (2007). Radical scavenging and singlet oxygen quenching activity of marine carotenoid fucoxanthin and its metabolites. Journal of agricultural and food chemistry, 55(21), 8516-8522.

Seely, G. R., Duncan, M. J., \& Vidaver, W. E. (1972). Preparative and analytical extraction of pigments from brown algae with dimethyl sulfoxide. Marine Biology, 12(2), 184-188.

Shiratori, K., Ohgami, K., Ilieva, I., Jin, X. H., Koyama, Y., Miyashita, K., Yoshida K., Kase S., \& Ohno, S. (2005). Effects of fucoxanthin on lipopolysaccharide-induced inflammation in vitro and in vivo. Experimental eye research,81(4), 422-428.

Sindhu, E. R., Preethi, K. C., \& Kuttan, R. (2010). Antioxidant activity of carotenoid lutein in vitro and in vivo. Indian Journal Of Experimental Biology 48: 843-848.

Sivaramakrishnan, T., Swain, S., Saravanan, K., Roy, S. D., Biswas, L., \& Shalini, B. (2017). 
In vitro antioxidant and free radical scavenging activity and chemometric approach to reveal their variability in green macroalgae from south Andaman Coast of India. Turkish Journal of Fisheries and Aquatic Sciences, 17(3), 641-651.

Sudhakar, M. P., Ananthalakshmi, J. S., \& Nair, B. B. (2013). Extraction, purification and study on antioxidant properties of fucoxanthin from brown seaweeds. Journal of Chemical and Pharmaceutical Research 5(7): 169-175.

Tang, Y. C. and B. H. Chen (2000). Pigment change of freeze-dried carotenoid powder during storage. Food Chemistry 69(1): 1117.

Thrane, J. E., Kyle, M., Striebel, M., Haande, S., Grung, M., Rohrlack, T., \& Andersen, T. (2015). Spectrophotometric analysis of pigments: a critical assessment of a highthroughput method for analysis of algal pigment mixtures by spectral deconvolution. PloS one, 10(9), e0137645.

Tutour, B., Benslimane, F., Gouleau, M. P., Gouygou, J. P., Saadan, B., \& Quemeneur, F. (1998). Antioxidant and prooxidant activities of the brown algae, Laminaria digitata, Himanthalia elongata, Fucus vesiculosus, Fucus serratus and Ascophyllum nodosum. Journal of Applied Phycology. 10: 121-129.

Vairappan, C. S., Daitoh, M., Suzuki, M., Abe, T., \& Masuda, M. (2001). Antibacterial halogenated metabolites from the Malaysian Laurencia species. Phytochemistry, 58(2), 291-297.

Wright, S. W. (1991). Improved HPLC method for the analysis of chlorophylls and carotenoids from marine phytoplankton. Marine Ecology Progress Series 77: 183196.

Yan, X., Chuda, Y., Suzuki, M., \& Nagata, T. (1999). Fucoxanthin as the major antioxidant in Hijikia fusiformis, a common edible seaweed. Bioscience, biotechnology, and biochemistry, 63(3), 605-607.
Zhu, Z., Wu, Q., Di, X., Li, S., Barba, F. J., Koubaa, M., Roohinejad S., Xiong X., \& $\mathrm{He}$, J. (2017). Multistage recovery process of seaweed pigments: Investigation of ultrasound assisted extraction and ultrafiltration performances. Food and Bioproducts Processing, 104, 40-47. 